\title{
Pemindaian QR Code Untuk Aplikasi Penampil Informasi Data Koleksi Di Museum Sangiran Sragen Berbasis Android
}

\author{
I Gusti Banjar Jawi \\ Jurusan Informatika Universitas Muhammadiyah Surakarta (UMS) Surakarta, Indonesia \\ igustibanjarjawi@gmail.com \\ Heru Supriyono \\ Jurusan Informatika Universitas Muhammadiyah Surakarta (UMS) Surakarta, Indonesia \\ Heru.Supriyono@ums.ac.id
}

\begin{abstract}
Abstraksi- Dengan berkembangnya teknologi smartphone saat ini, informasi yang dibutuhkan menjadi sangat mudah untuk didapatkan. Museum sebagai tempat informasi yang sering dikunjungi adalah tempat yang cocok untuk mencari informasi tentang zaman purbakala. $Q R$ Code adalah salah satu cara untuk mendapatkan informasi yang lengkap. $Q R$ Code yaitu suatu jenis image dua dimensi yang menampilkan data berupa teks. Tujuan penelitian ini adalah untuk memberi kemudahan pengunjung dalam mencari informasi koleksi museum. Metode yang digunakan dalam penelitian ini adalah dengan metode System Development Life Cycle (SDLC). Dalam pembuatan sistem ini antara lain membuat web museum kemudian dihostingkan dan membuat aplikasi melalui app inventor 2 ultimate secara offline, kemudian membuat $Q R$ Code yang didalamnya terdapat $U R L$ web museum. Hasil dari penelitian ini adalah sistem web museum. Pada sistem ini terdapat fitur seperti Home, Koleksi, dan Admin. Berdasarkan hasil pengujian sistem ini melalui black-box, smartphone, dan responden dapat disimpulkan bahwa fitur web museum sudah sesuai, dan pengujian pada smartphone disimpulkan bahwa sistem ini dapat berjalan dengan baik. Berdasarkan pengujian kepada pengunjung museum dapat diketahui sebanyak 79\% responden setuju bahwa sistem ini layak untuk digunakan.
\end{abstract}

Katakunci-smartphone; museum; qr code; app invetor 2 ultimate; offline; url

\section{Pendahuluan}

Seiring dengan perkembangan teknologi zaman sekarang, kegiatan manusia untuk mencari informasi dapat dimudahkan dengan memanfaatkan teknologi smartphone. Karena teknologi smartphone kedepannya akan terus berkembang berdasarkan apa yang dibutuhkan manusia saat itu. Pada tahun 2010 terdapat peningkatan pangsa pasar Android lebih dari $700 \%$ yang terdapat nominal penjualan smartphone sebanyak 67.224.500 unit ( Sugiantoro \& Hasan, 2015).

Dengan kemajuan teknologi yang dimiliki android, maka pencarian informasi yang dibutuhkan akan lebih cepat ditemukan. Dengan android pengguna dapat mencari informasi apa saja yang dibutuhkan tanpa perlu menggunakan Personal Computer (PC) atau laptop karena aplikasi yang dimiliki oleh android hampir sama pada PC atau laptop (Murtiwiyati dkk, 2013). Untuk memberi kemudahan pada pengguna, maka diciptakan sebuah cara baru yaitu dengan menggunakan Quick Response (QR) Code atau dapat disebut dengan kode respon cepat.

QR Code adalah suatu jenis image dua dimensi yang menampilkan data berupa teks. Dengan QR Code pengguna dapat mengakses suatu web lebih cepat daripada harus melakukan secara manual (Dagan dkk, 2016). Menurut penelitian yang dilakukan oleh Bajpai (2015), QR Code dapat didaur ulang dan digunakan kembali. Menggunakan 
QR Code harus pada tempat yang terang atau pencahayaan yang cukup agar kode pada $Q R$ Code terbaca oleh pemindai. QR Code mampu menampung banyak informasi dengan 7.089 karakter numerik dan 4296 karakter alfanumerik (Narayanan, 2012). Pemindaian QR Code juga dapat digunakan sebagai sistem keamanan untuk tempat tertentu yang boleh dimasuki orang-orang tertentu seperti ruang riset ataupun ruang pusat (Supriyono dkk, 2013).

Museum adalah tempat yang banyak informasi bersejarah yang harus diketahui, tempat yang memiliki koleksi-koleksi barang langka pada zaman purbakala. Menurut penelitian yang dilakukan oleh Jevremovic dkk (2012), menyatakan bahwa penerapan QR Code pada museum dapat mengubah cara berkomunikasi terhadap warisan budaya. Disini penulis mencoba melakukan observasi pada Museum Purbakala Sangiran, Museum Purbakala Sangiran adalah museum arkeologi yang terletak di Kalijambe, Kabupaten Sragen, Jawa Tengah. Situs Sangiran memiliki luas mencapai $56 \mathrm{~km}^{2}$ meliputi tiga kecamatan di Sragen (Gemolong, Kalijambe, dan Plupuh). Situs Sangiran mempunyai 3 ruang koleksi pamer, (1) pada ruang 1 adalah ruang koleksi pamer yang meliputi tengkorak manusia purba, alat batu, dan hewan purba yang pernah hidup di Sangiran, (2) pada ruang 2 adalah ruang koleksi pamer yang meliputi tentang pengetahuan purbakala, dan (3) pada ruang 3 adalah ruang yang berisi tentang pengertian kelompok manusia yang pernah hidup di Sangiran. Situs Sangiran merupakan tempat rekreasi edukasi yang sering dikunjungi oleh sekolah maupun universitas serta masyarakat umum yang ingin tahu tentang zaman purbakala. Permasalahan yang dihadapi sekarang adalah pada setiap ruangan koleksi pamer tidak memberikan infromasi secara lengkap sedangkan permasalahan yang lain adalah sulitnya pengunjung yang ingin menyimpan informasi tersebut untuk dipelajari. Penulis mempunyai ide untuk membuat QR Code pada benda koleksi pamer agar dapat memberikan informasi yang secara detail dan mudah untuk dipelajari. Dengan adanya sistem ini diharapkan dapat membantu pengunjung yang berada di Museum Sangiran mendapat informasi yang diperlukan dengan cara yang sederhana, sehingga pengunjung tidak perlu repot untuk mencatat informasi yang diperlukan.

\section{DASAR TEORI DAN TinJaUAn PUSTAKA}

Teknologi yang dipakai dalam sistem aplikasi ini yakni menggunakan QR Code. Quick Response (QR) Code atau dapat disebut dengan kode respon cepat adalah suatu jenis image dua dimensi yang menampilkan data berupa teks dengan tujuan untuk menyampaikan informasi dengan cepat dan mendapatkan respon yang cepat. Fungsionalitas utama QR Code dapat dengan mudah dibaca oleh pemindai..

\section{Metode PenElitian}

Untuk membantu pengelolaan informasi pada benda koleksi pamer museum, digunakanlah sistem aplikasi yang memanfaatkan QR Code. Sistem ini akan diterapkan pada Museum Purbakala Sangiran Sragen. Metode yang digunakan adalah System Development Cycle (SDLC) dengan pendekatan model Waterfall, seperti pada Gambar 1.

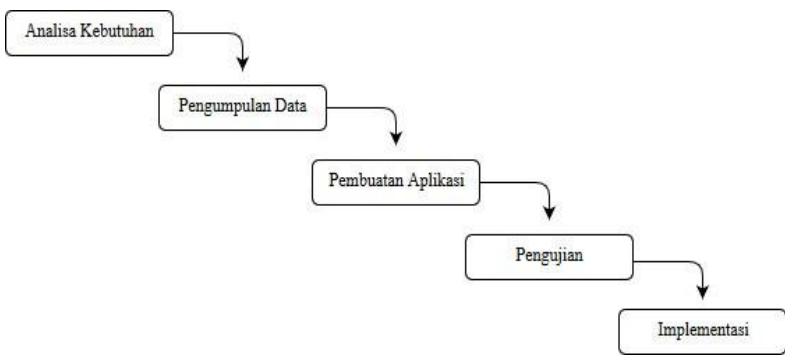

Gambar 1. Metode Waterfall

\section{HASIL DAN PEMBAHASAN}

\section{A. Hasil Tampilan}

Pada Gambar 2 menunjukkan hasil dari perancangan desain web pada desktop laptop atau komputer dan pada Gambar 3 menunjukkan hasil desain web pada smartphone. 

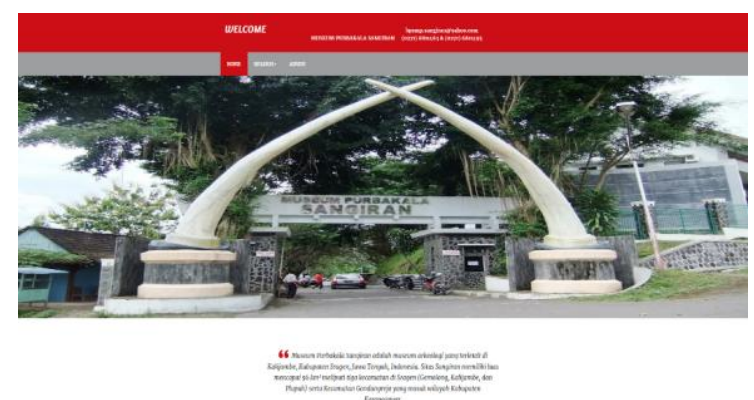

Gambar 2. Tampilan web pada desktop

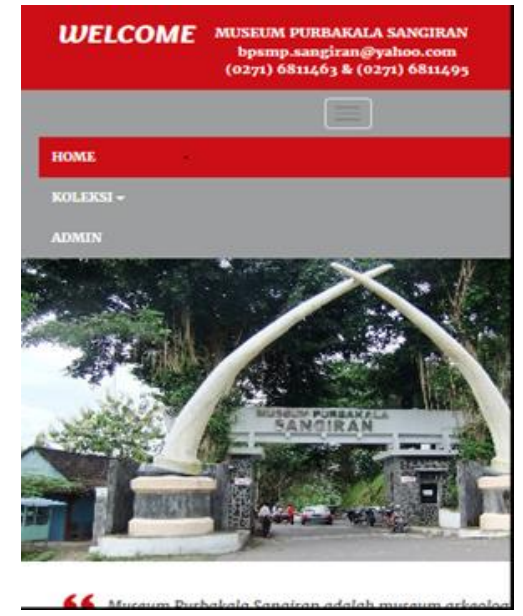

Gambar 3. Tampilan web pada smartphone

\section{B. Pengujian sistem pada smartphone}

Pada pengujian ini untuk mengetahui sistem yang dibuat dapat berjalan dengan baik terhadap beberapa smartphone. Seperti ditunjukkan pada Tabel 1 .

Tabel 1. Uji coba pada smartphone

\begin{tabular}{|c|c|c|c|c|}
\hline No & Merk Smarphone & Spesifikasi & Os Android & Hasil \\
\hline 1 & Asus Zenfone 3 Max & $\begin{array}{l}\text { Screen } 5.5 \text { inch resolusi } 1080 \times 1920 \\
\text { pixels, CPU 1.4 GHz Cotex-A53, RAM } \\
\text { 3GB }\end{array}$ & Android Nougat & Berjalan Baik \\
\hline 2 & Asus Zenfone 4 & $\begin{array}{l}\text { Screen } 4.0 \text { inch resolusi } 480 \times 800 \\
\text { pixels, CPU Dual-core } 1.2 \mathrm{GHz}, \\
\text { RAM 1GB }\end{array}$ & Android Lolipgr & Berjalan Baik \\
\hline 3 & Samsung Core 1 & $\begin{array}{c}\text { Screen } 4.3 \text { inch resolussi } 480 \times 800 \\
\text { pixels, CPU Dual-core } 1.2 \mathrm{GHz} \\
\text { Cortex-A5, RAM 1GB }\end{array}$ & $\begin{array}{c}\text { Android Jelly } \\
\text { Bean }\end{array}$ & Berjalan Baik \\
\hline 4 & Lenovo A6000 & $\begin{array}{l}\text { Screen } 5.0 \text { inch resolusi } 720 \times 1280 \\
\text { pixels, CPU Quad-core } 1.2 \mathrm{GHz} \\
\text { Cortex-A53, RAM 1GB }\end{array}$ & Android KitKat & Berjalan Baik \\
\hline 5 & Xiaomi Redmi Pro & $\begin{array}{c}\text { Screen 5,5 inch resolusi 1080×1920 } \\
\text { pixels, CPU Mediatek MT6797T } \\
\text { Helio X25, RAM 4GB }\end{array}$ & $\begin{array}{c}\text { Android } \\
\text { Marshmallow }\end{array}$ & Berjalan Baik \\
\hline
\end{tabular}

\section{KESIMPULAN}

Setelah dilakukan pengujian black-box dapat disimpulkan sebagai berikut:

1. Sistem dapat berjalan dengan baik dan fungsi fitur sudah sesuai dengan yang diinginkan.
2. Aplikasi dapat berjalan dengan lancar pada smartphone dengan kapasitas RAM yang memadai.

3. Hasil pemindaian QRCode dapat dipengaruhi oleh kecepatan koneksi internet.

4. Jarak yang ideal untuk pemindaian QRCode yaitu paling dekat $\pm 10 \mathrm{~cm}$ dan $\pm 45 \mathrm{~cm}$ untuk jarak yang jauh.

Untuk mengoptimalkan sistem ini, pengguna lebih baik menggunakan smartphone yang mempunyai kapasitas RAM minimal 1GB untuk mendapatkan hasil yang baik dan kecepatan koneksi yang mumpuni. Sistem ini sangat mudah untuk di akses melalui komputer dan smartphone, sehingga pihak museum dan pengunjung dapat terbantu untuk memperoleh informasi tentang Museum Sangiran Sragen..

\section{Daftar Pustaka}

[1] Bajpai, M.K. (2015). Researching throught QR Codes in Libraries, International Symponisum on Energing and Technologies in Libraries and Information Services, 291-294, DOI: 10.1109/ETTLIS.2015.7048214.

[2] Dagan, I. Binyamin, G. \& Eilam, A. (2016). Delivery of QR Codes to Cellurar Phones throught Data Embedding in Audio, International Conference on the Science of Electrical Engineering, DOI: 10.1109/ICSEE.2016.7806076.

[3] Jevremovic, V. \& Petrovski, S. (2012) MUZZEUM - Augmented Relaity and QR Codes Enabled Mobile Platform with Digital Library, usesd to Guerrilla Open the National Museum of Serbia, International Conference on Virtual Systems and Multimedia, DOI: 10.1109/VSMM.2012.6365977.

[4] Murtiwiyati, \& Lauren G. (2013). Rancang Bangun Aplikasi Pembelajaran Budaya Indonesia Untuk Anak Sekolah Dasar Berbasis Android, Jurnal Ilmiah KOMPUTASI, 12(2), Desember 2013, ISSN: 1412-9434.

[5] Narayanan, A.S. (2012). QR Codes and Security Solutions, International Journal of Computer Science and Telecommunications, 3(7), 69-72, July
2012, ISSN: 2047-3338.

[6] Sugiantoro, B. \& Hasan, F. (2015). Pengembangan QR Code Scanner Berbasis Android Untuk Sistem Informasi Museum Sonobudoyo Yogyakarta TELEMATIKA, 12(02), 134 145, Juli 2015, ISSN: 1829-667X.

Supriyono, H. Kurniawan, A. \& Rakhmadi, A. (2013). Perancangan dan Pembuatan Sistem Pintu Otomatis Menggunakan Barcode, KomuniTi, 5(1), Maret 2013. 